\title{
"Nunca Me Falaram sobre Isso!": o Ensino das Sexualidades na Perspectiva de Estudantes de uma Escola Federal de Medicina
}

\author{
"I've Never Been Told about That!": the \\ Teaching of Sexualities from the Perspective \\ of Undergraduates at a Federal Medical \\ School
}

Alexandre Costa Val ${ }^{1 \odot}$ Leonardo Mendes Mesquita Vinícius de Abreu Rocha ${ }^{I}$ Hugo Alejandro Cano-Prais ${ }^{I}$ Gustavo Meirelles Ribeiro ${ }^{I}$

\section{PALAVRAS-CHAVE}

- Educação Médica.

- Sexualidade.

- Estudantes de Medicina.

- Currículo.
Estudantes e profissionais de saúde se mostram embaraçados ao se depararem com questões relativas às sexualidades de seus pacientes. Diante disso, não é incomum o estabelecimento de uma relação superficial, erros no diagnóstico e a impossibilidade de condução do tratamento. Pesquisas indicam que essa dificuldade decorre de uma formação inadequada dos profissionais, especialmente no que diz respeito ao cuidado de grupos vulneráveis, cujas experiências extrapolam os marcos heteronormativos hegemônicos que delimitam o campo sexual. No Brasil, poucos estudos buscaram compreender como esse assunto é tratado no ensino médico. Esta investigação se debruçou sobre essa questão e teve como objetivo conhecer, na perspectiva de estudantes de uma escola federal de Medicina, como os aspectos relacionados às sexualidades e aos gêneros são abordados em suas graduações. Trata-se de uma pesquisa qualitativa em que foram realizadas entrevistas semiestruturadas com 15 estudantes do último ano do curso. As falas foram gravadas, transcritas e examinadas por meio da análise de conteúdo. O diálogo entre as categorias empíricas que se sedimentaram ao longo da investigação e a literatura revelaram dificuldades dos alunos em lidar com um tema que não pode ser completamente apreendido por um saber técnico e operacional. A ideia de que não se fala sobre o assunto no curso de Medicina contribui para velar o fato de que se fala (e se fala muito) sobre tais questões. A abordagem, no entanto, se dá por um viés organicista, que contribui para a manutenção da crença em categorias binárias, naturalizadas e essencializadas, que reforçam as normas que regulam o campo da sexualidade. Apostando no protagonismo de todos aqueles envolvidos no ensino médico, discute-se, finalmente, a necessidade de alterações qualitativas no currículo que possibilitem a construção de novas formas de conhecimento e de atuação. Formas que, valorizando experiências, saberes e práticas pedagógicas diversas, possam romper com as dicotomias e com as hierarquias hegemônicas, transformando positivamente a realidade social. 


\section{KEY-WORDS}

- Medical Education.

- Sexuality.

- Medical Students.

- Curriculum.

Recebido em 24/7/19

Aceito em 27/7/19

A

\section{ABSTRACT}

Health undergraduates and professionals feel embarrassment when facing issues concerning the sexuality of their patients. As a result, it is not uncommon to see the establishment of a superficial relationship, errors in diagnoses and the impossibility of giving treatment. Studies show that this difficulty is due to inadequate education of these professionals, especially regarding vulnerable groups whose experiences lie beyond the hegemonic heteronormativity which delimits the sexual field. In Brazil, there is limited research which aims to comprehend how this subject has been tackled in medical school. This investigation examined this issue and its main objective was to understand, from the perspectives of undergraduates at a federal medical school, how aspects regarding sexuality and gender are approached in the course. This is a qualitative research involving semi-structured interviews conducted with fifteen students in their final year of the course. The interviews were recorded, transcribed and examined based on content analysis. The subjects of the formal curriculum were also been analyzed, separating the titles of the classes which involved exclusively biological aspects from those which involved psychosocial aspects. Each one of these groups has been considered in relation to the total of content of the curriculum in order to assist us with the analysis of the interviews. The dialogue between the empirical categories and the bibliography shows the difficulty undergraduates feel in dealing with a theme that cannot be completely apprehended by technical and operational knowledge. The idea that the theme is not discussed in medical school contributes to hiding the fact that such a topic is, in reality, widely discussed. However, the approach used is organicist, contributing to the maintenance of binary, naturalized, essentialist categories which reinforce the norms that regulate the field of sexuality. Advocating the pivotal role that all individuals involved in medical education play, we finally discuss the need for qualitative changes in the curriculum which would enable us to build new forms of knowledge and performance. By valuing experiences, expertise and diverse pedagogical practices, these new forms can rupture the hegemonic dichotomies and hierarchies in order to positively transform social reality.

\section{INTRODUÇÃO}

A sexualidade, concebida como experiência que envolve aspectos físicos, psíquicos, sociais e relacionais, constitui um importante pilar da saúde do ser humano ${ }^{1}$. Além de sua influência na qualidade de vida do indivíduo e em suas relações interpessoais, as crescentes demandas sociais e políticas de certos grupos que se organizam em torno dessa questão indicam a necessidade de que o campo da saúde desenvolva novas formas de compreensão e atuação em relação a esse tema ${ }^{2-4}$.

É habitual que estudantes e profissionais que se dedicam ao cuidado em saúde se mostrem embaraçados diante de demandas relacionadas à esfera sexual de seus pacientes. A não abordagem do tema, o estabelecimento de uma relação superficial, os erros no diagnóstico e, até mesmo, a impossibilidade de condução do tratamento ${ }^{3,5-7}$ são alguns dos reflexos na assistência da população geral. Em se tratando de grupos vulneráveis, cujas experiências extrapolam os marcos hetero- normativos hegemônicos do campo sexual, a situação é ainda pior. Essa população heterogênea, conhecida genericamente pela sigla LGBT (lésbicas, gays, bissexuais, travestis e transexuais), se depara com diversas barreiras no acesso aos serviços de saúde, incluindo desconhecimentos, preconceitos e resistências por parte dos profissionais ${ }^{4,8}$.

Estudos ${ }^{2,3,5-7}$ apontam que há insuficiência na formação desses trabalhadores para lidar com essas questões, indicando a importância de investimentos nessa área para melhoria da assistência. Especificamente em relação aos cursos de Medicina, inquéritos internacionais foram realizados para conhecer quantas escolas médicas oferecem o ensino da sexualidade durante a graduação, os assuntos ofertados e o tempo despendido para isto. Observa-se que, em geral, o tema tende a ser tratado pontualmente, de forma fragmentada, priorizando a matriz biológica dos corpos e sem articulação com outros campos do saber. Essa abordagem contribui para reforçar pre- 
conceitos que têm, em sua esteira, a crença em entidades dicotômicas, naturalizadas e predefinidas ${ }^{6-8}$.

No Brasil, há poucas investigações a respeito dessa questão $0^{3,9-15}$, sendo que a maioria apresenta uma abordagem eminentemente quantitativa. Um dos maiores levantamentos nacionais $^{3}$ evidenciou que 96,3\% dos professores de 110 escolas médicas brasileiras ofertam temas relacionados às sexualidades, com uma duração de menos de seis horas por disciplina e sem integração entre elas. Os temas relacionados aos aspectos fisiopatológicos - como as Infecções Sexualmente Transmissíveis (ISTs) e as disfunções sexuais - são privilegiados em detrimento de outros relacionados às diversidades sexuais e seus componentes psicológicos, sociais, históricos e políticos.

Além dos efeitos no cuidado individual, esse tipo de formação se reflete na forma como serviços e políticas públicas de saúde são operacionalizados. As práticas assistenciais apoiadas nas políticas de saúde para mulheres, por exemplo, permanecem, desde 1980, fortemente focadas no pré-natal, no parto, no puerpério, no climatério, no planejamento familiar, nas ISTs e nos cânceres de colo de útero e de mama ${ }^{16}$. Com os homens, a situação não é diferente. Ações de cuidado em saúde voltadas a esse público, de forma habitual, se dirigem exclusivamente ao sistema urogenital, produzindo um tipo idealizado de homem cuja presença do pênis coloca a virilidade e a heterossexualidade como destinos inexoráveis ${ }^{17}$. Essas abordagens revelam como nuances relacionadas aos gêneros e às sexualidades são reduzidas ao corpo biológico, impedindo um acolhimento mais holístico e integralizado da população.

Tais constatações se tornam especialmente preocupantes quando lidas no contexto das Diretrizes Curriculares Nacionais do Curso de Graduação em Medicina ${ }^{18}$ para elaboração dos currículos médicos. Estas, embora não sejam claras na forma como se deve abordar o tema, preconizam uma formação que contemple as diversidades de gêneros, de orientações sexuais e demais aspectos que singularizam cada pessoa ou grupo social. Há, portanto, um descompasso entre o ideal e a prática que merece ser mais bem investigado.

Apoiados nos estudos de Foucault ${ }^{19}$, tomaremos a sexualidade como uma experiência atravessada por uma rede de enunciados e ações que, em última instância, exerce um controle sobre os corpos e as subjetividades. Trata-se de uma forma de poder cuja versão mais efetiva se revela mais por meio da produção de discursos, práticas e saberes do que pela via da repressão ou do silenciamento. A construção do saber médico, nessa perspectiva, ao consolidar um conjunto de conhecimento socialmente legitimado, ocupa um lugar privilegiado para entendimento desse fenômeno.
Seguindo essa indicação, buscamos compreender, na perspectiva de estudantes do curso de Medicina de uma universidade pública, como se dá essa construção durante a graduação. O que estudantes dizem sobre a temática, especialmente no tocante às experiências que questionam as normas binárias e heteronormativas? Como constroem esse saber? Ou, ainda, como gostariam que o assunto fosse abordado em sua formação? Acreditamos que o material produzido com base nesses questionamentos possa contribuir para uma discussão sobre esse importante aspecto do ensino médico.

\section{Percurso metodológico}

Trata-se de uma pesquisa qualitativa, dado seu potencial para investigar processos sociais de grupos específicos ${ }^{20}$. Em nosso caso, estávamos interessados em apreender a percepção de estudantes de Medicina em relação ao conhecimento e ao cuidado das sexualidades, com foco em suas crenças, representações, experiências, comportamentos e práticas. Para melhor nos aproximar do objeto, integramos dois acadêmicos do curso investigado à nossa equipe de trabalho. Essa estratégia facilitou o acesso aos participantes, assim como o fluxo das narrativas e a precisão de referenciais êmicos no processo de análise.

A seleção dos estudantes foi intencional, tendo como critério de inclusão estar no último ano $\left(11^{\circ}\right.$ e $12^{\circ}$ períodos $)$ da graduação em Medicina da Universidade Federal de Ouro Preto (Ufop), Minas Gerais. Esses alunos, por já terem cursado as principais disciplinas obrigatórias, estariam em melhores condições para nos dar um panorama da formação em questão. O estudo foi aprovado pelo Comitê de Ética e Pesquisa Institucional (CAAE 68393517000005150).

Por meio de uma lista de matrícula, fizemos contato pessoal ou telefônico com alunos, buscando compor um grupo heterogêneo de participantes, sobretudo em relação a gênero e idade. Na ocasião, explicamos a pesquisa e os convidamos para uma entrevista baseada em roteiro semiestruturado ${ }^{20}$, composto por perguntas-chave que visavam desencadear uma fala espontânea, sem fechar demasiadamente o campo. Dos 25 contatados, oito se recusaram a participar: quatro por não se sentirem à vontade para falar sobre o tema e quatro por indisponibilidade de horário. Dois deles não nos responderam. Os convites foram encerrados quando, durante as análises, chegamos ao consenso de que as reincidências e complementaridade das informações eram suficientes para atender aos nossos objetivos ${ }^{20}$.

Também analisamos os programas de disciplinas do curso, selecionando títulos de temas relacionados às diversas dimensões da sexualidade. Separamos aqueles que envolviam 
exclusivamente aspectos biológicos e aqueles que abarcavam aspectos psicossociais, contabilizado percentualmente cada um dos grupos em relação à totalidade de temas do currículo.

As entrevistas ocorreram entre novembro de 2017 e dezembro de 2018, em locais privativos de acordo com a preferência dos alunos. A duração média foi de 40 minutos. Todas elas foram gravadas e transcritas pelos pesquisadores. Identificamos cada um dos participantes com a letra "E" e um número arábico para preservar o anonimato (Quadro 1).

\begin{tabular}{|c|c|c|c|c|}
\hline \multicolumn{5}{|c|}{$\begin{array}{c}\text { QUADRO } 1 \\
\text { Perfil dos estudantes entrevistados }\end{array}$} \\
\hline Entrevistado & Gênero & $\begin{array}{l}\text { Idade } \\
\text { (anos) }\end{array}$ & Período & Naturalidade \\
\hline E1 & $\begin{array}{c}\text { Cis* / } \\
\text { Masculino }\end{array}$ & 26 & $12^{\mathrm{o}}$ & Capital (MG) \\
\hline E2 & $\begin{array}{c}\text { Cis* / }^{*} \\
\text { Masculino }\end{array}$ & 21 & $11^{\circ}$ & Capital (MG) \\
\hline E3 & $\begin{array}{c}\text { Cis* / } \\
\text { Feminino }\end{array}$ & 29 & $12^{\mathrm{o}}$ & Interior (ES) \\
\hline E4 & $\begin{array}{c}\text { Cis* / } \\
\text { Feminino }\end{array}$ & 27 & $11^{\circ}$ & Capital (MG) \\
\hline E5 & $\begin{array}{c}\text { Cis* / } \\
\text { Feminino }\end{array}$ & 25 & $11^{\circ}$ & Interior (MG) \\
\hline E6 & $\begin{array}{c}\text { Cis* / } \\
\text { Feminino }\end{array}$ & 28 & $12^{\circ}$ & Interior (MG) \\
\hline E7 & $\begin{array}{l}\text { Cis*/ } \\
\text { Masculino }\end{array}$ & 25 & $11^{\circ}$ & Interior (SP) \\
\hline E8 & $\begin{array}{c}\text { Cis* / } \\
\text { Masculino }\end{array}$ & 24 & $11^{\circ}$ & Interior (GO) \\
\hline E9 & $\begin{array}{c}\text { Cis* / } \\
\text { Masculino }\end{array}$ & 25 & $11^{\mathrm{o}}$ & Interior $(\mathrm{MG})$ \\
\hline E10 & $\begin{array}{c}\text { Cis* / } \\
\text { Feminino }\end{array}$ & 32 & $12^{\mathrm{o}}$ & Interior (MG) \\
\hline E11 & $\begin{array}{c}\text { Cis* / }^{*} \\
\text { Feminino }\end{array}$ & 25 & $11^{\circ}$ & Interior (MG) \\
\hline E12 & $\begin{array}{c}\text { Cis* / }^{*} \\
\text { Feminino }\end{array}$ & 26 & $11^{\mathrm{o}}$ & Interior (MG) \\
\hline E13 & $\begin{array}{c}\text { Cis* / } \\
\text { Feminino }\end{array}$ & 32 & $12^{\mathrm{o}}$ & Interior (MG) \\
\hline E14 & $\begin{array}{c}\text { Cis* / } \\
\text { Masculino }\end{array}$ & 25 & $11^{\circ}$ & Interior (MG) \\
\hline E15 & $\begin{array}{c}\text { Cis* / } \\
\text { Masculino }\end{array}$ & 26 & $11^{\circ}$ & Interior (MG) \\
\hline
\end{tabular}

Fonte: Confeccionado pelos autores.

${ }^{*}$ *is se refere à pessoa cisgênera, que, diferentemente da transgênera, se identifica com o sexo/gênero que the foi designado no nascimento.

As transcrições foram lidas exaustivamente por cada um dos pesquisadores, buscando localizar repetições e falas inéditas de acordo com os propósitos da pesquisa. Seguindo a perspectiva da análise de conteúdo de Bardin ${ }^{21}$, localizamos núcleos temáticos organizados em torno de expressões ou palavras em função das quais os conteúdos das falas se estabeleceram. Após compararmos as análises preliminares, agre- gamos alguns desses núcleos e estabelecemos categorias empíricas maiores ("o saber"; "o ensino médico" e "propostas"), responsáveis pela especificação do tema. Forjamos, finalmente, inferências e interpretações, inter-relacionando-as com nossas vivências no campo e com a literatura sobre o assunto, no intuito de fomentar discussões em torno de novas dimensões teóricas e interpretativas sugeridas pelo material.

\section{DISCUSSÃO E RESULTADOS}

\section{O saber}

Discutimos nesta categoria o conhecimento dos estudantes a respeito de diferentes aspectos relativos à sexualidade, assim como a forma como esse saber foi construído e materializado nas práticas cotidianas. De forma geral, foram recorrentes declarações de desconhecimento ou de dificuldade no tratamento do tema, especialmente no que se refere à delimitação ou formulação de alguns conceitos. Termos como "polêmico", "delicado", "complexo" e "tabu" foram frequentemente utilizados para caracterizar o campo da sexualidade, refletindo uma postura de defesa diante de algo que não é completamente apreendido pela racionalidade instrumental que domina a formação médica ${ }^{4,5,9,22}$.

Quando incitados, os participantes ressaltaram a complexidade da sexualidade, indicando que, além dos aspectos biológicos, há o envolvimento de diversas formas de expressão advindas do tensionamento entre desejos individuais e processos sócio-históricos coletivos:

\footnotetext{
Como sexualidade, eu entendo uma coisa muito ampla. Tanto a questão de atração física, mesmo, a parte de sexo, quanto a questão comportamental, a questão social. Então, como a pessoa se mostra pro mundo, como a pessoa se enxerga, como a pessoa enxerga o outro, enxerga o corpo do outro, se relaciona com o corpo do outro. (E11)
}

Observamos, no entanto, dificuldades na definição de elementos mais específicos, tais como "sexo", "gênero" e "orientação sexual". A maioria não fez qualquer diferenciação entre esses termos ou os usou como equivalentes:

[...] gênero eu classificaria como o gênero que a pessoa nasceu, talvez biológico, não sei. [...] E a orientação, diversas: homossexual, bissexual, hétero, trans. (E6)

Tal constatação indica a tendência em supor uma continuidade entre sexo-gênero-desejo que reforça e naturaliza uma lógica binária apoiada na anatomia. Ou seja, um corpo identificado como macho ou como fêmea determina um gêne- 
ro - masculino ou feminino - que, por sua vez, pressupõe um desejo orientado ao sexo/gênero oposto. Essa ordenação, sustentada na concepção de que o sexo é um dado estável e pré-discursivo, cria uma categoria de inteligibilidade dos corpos que deixa aqueles que a subvertem à margem do sistema ${ }^{23}$. A tentativa de classificar as expressões que escapam a essas "normas de gênero"24 é sempre precária e insuficiente:

Que vergonha não saber nada! Comparando com a transexualidade, acho que o transexual não consegue se identificar com o gênero com o qual ele nasceu, e o travesti se identifica, lida até bem com o gênero que nasceu, mas transita também pro outro gênero. (E4)

Eles [travestis] são homossexuais, só que mais do que isso, eles não só vivem como homossexuais, eles se comportam como tal, eles têm como se fosse um personagem assim. (E5)

Essas falas mostram como alguns termos podem ser valorizados em detrimento de outros, ofuscando aspectos socioculturais que fazem parte de nossas construções particulares. É notável, por exemplo, como a definição das transexualidades, entidade chancelada pelo discurso biomédico numa vertente patologizante, causa menos embaraço que a definição de uma categoria usada especificamente no Brasil: a "travesti". Ainda que essa nomeação carregue diversos estigmas - como a ideia de que se trata de um homem vestido de mulher representada na fala por meio do artigo "o" e não "a" travesti -, os movimentos sociais têm se utilizado dela para ressaltar o caráter político desses corpos femininos heterogêneos que sempre foram excluídos da sociedade $e^{4,25}$.

Isso não significa que não existam diversas nuances nas apresentações das travestilidades, que jamais serão reduzidas a um termo ou a alguma experiência particular. Essas categorias artificialmente construídas, por mais que possam ser operativas na compreensão da temática, são insuficientes para abarcar as singularidades que transitam no cotidiano da assistência em saúde ${ }^{25,26}$. Nesse sentido, a prática clínica requer, além de vivência ou formação técnica, uma postura de empatia do profissional que facilite a interação com o paciente capaz de promover trocas e redefinições de saberes preestabelecidos ${ }^{14,15}$. O ensino médico, no entanto, ao incutir no aluno a ideia de que há de se ter respostas objetivas para tudo ${ }^{4,22}$, não contribui para que, diante do "não saber", em vez de ficar envergonhado, ele pergunte a cada paciente como este se identifica e o que isso significa para ele. Esse deslocamento pode contribuir não só para explorar novas formas de conhecimento e de atuação, mas também para desestabilizar hierarquias reproduzidas nos campos da educação e da saúde, modificando positivamente a realidade social ${ }^{15,25-27}$.

Seguindo esse caminho, buscamos entender como os participantes estabeleceram algum saber sobre as diversidades relativas às sexualidades e aos gêneros. A maioria descreveu as vivências pessoais e relacionais, notadamente aquelas possibilitadas por interações no ambiente universitário, como as principais desencadeadoras de um processo particular de conhecimento. Incitados por experiências, seja com a própria sexualidade, com a sexualidade de seus colegas ou com a de seus pacientes, alguns buscaram ativamente algum tipo de informação em redes sociais, meios de comunicação em massa ou cursos extracurriculares:

\begin{abstract}
Depois disso [entrada na universidade], eu comecei a tentar entender um pouco mais. Mas principalmente depois que eu comecei a ter contato no curso com pessoas que precisavam de uma orientação. [...] Aí participei de alguns simpósios, de alguns workshops, de alguns encontros que discutiam essa temática. (E1)
\end{abstract}

Todos identificaram essas diferentes formas de sensibilização como oportunidade de desconstrução de preconceitos relativos à diversidade sexual. Sem um direcionamento, no entanto, os efeitos dessas vivências podem ser positivos ou negativos, de acordo com a elaboração de cada um ${ }^{7}$. Muitos discursos, por exemplo, apresentaram conteúdos influenciados pelo senso comum e/ou por ideais conservadores e moralizantes:

Acho que [a sexualidade] envolve definição pessoal de gênero, de escolha, se a pessoa quer ser homossexual, bissexual [...] porque ela [uma lésbica] era o homem da relação, digamos assim. [...] e ela andava igual homem mesmo, camisetão, short largo. (E5)

Na minha cidade era muito raro, isso [homossexualidade] não existia no colégio. Era uma coisa muito errada. Da mesma forma que usar droga ilícita era uma coisa muito rara e eu não via isso de jeito nenhum. (E8)

Essas falas revelam o aspecto moral que envolve concepções e julgamentos a respeito da diversidade sexual. Tal questão nem sempre é evidente, tendo em vista o seu velamento por discursos "científicos", que, em última instância, buscam controlar os corpos e o espaço social ${ }^{19}$. Não é por acaso que, quando questionados a respeito das especificidades das demandas em saúde da população LGBT, os participantes elen- 
caram, em ordem decrescente de recorrência: o atendimento em Saúde Mental para todos; o processo transexualizador para pessoas travestis e transexuais; as formas de prevenção de Infecções Sexualmente Transmissíveis (ISTs) de acordo com as particularidades de cada grupo; a assistência ginecológica e o planejamento familiar para mulheres (incluindo lésbicas e bissexuais) e o uso do nome social nos serviços de saúde para pessoas travestis e transexuais.

É notável como a dimensão técnica e objetiva, amparada na biologia e fisiologia dos corpos, ganha relevo em detrimento dos aspectos subjetivos e sócio-históricos que envolvem a diversidade das experiências sexuais. Tais achados estão em consonância com estudos que problematizam o viés orgânico e patológico da abordagem do tema nas escolas médicas ${ }^{3,13}$, que culmina na associação direta das experiências que não se enquadram nas "normas de gênero" 24 ao desvio ou ao transtorno mental, assim como às ISTs I, $, 814,25^{\text {. }}$

Para desvendar um pouco mais essa questão, perguntamos aos alunos: Como e em quais disciplinas ocorreu algum tipo de alusão à sexualidade? Quais foram suas sensações e impressões em relação ao tratamento da temática? O que se aprendeu com essas experiências?

\section{O ensino médico}

Todos os entrevistados reconheceram que há alguma abordagem - ainda que insuficiente - sobre a sexualidade no curso de Medicina. As disciplinas do núcleo de Saúde Mental foram as mais citadas, sendo que o assunto foi tratado em aulas teóricas expositivas, grupos de discussão e atendimentos ambulatoriais. Também houve referências pontuais às práticas assistenciais que ocorreram na Clínica Médica, Pediatria, Medicina de Família e Comunidade e Saúde da Mulher. Alguns destacaram que, nessa última, houve algumas exposições teóricas de temas focados em aspectos orgânicos e reprodutivos, como, por exemplo, métodos contraceptivos.

Em relação às práticas nos atendimentos ambulatoriais, foram frequentes falas que indicavam despreparo de todos aqueles envolvidos na assistência:

A gente não está preparado, nenhum profissional, nem da recepção, nem da enfermagem, nem médicos, acadêmicos... então, quando chega a pessoa, ela se sente desconfortável. (E3)

O desconforto, presente tanto do lado dos alunos como dos pacientes, é, aqui, localizado numa pessoa indefinida, embora, no decorrer da fala, fique claro que ela se refere às homossexualidades femininas, experiências particularmente invisibilizadas nas práticas assistenciais ${ }^{16,28}$.
Na ginecologia, eu achava que faltava muito, porque a gente atendia muitas mulheres e nunca era perguntado se elas mantinham relações sexuais com outras mulheres. [...] Porque a gente fala com as pacientes que são hétero os cuidados que devem tomar, mas não fala com aquelas que não são; é como se ignorasse isso ou como se não acontecesse nada. (E3)

O contato com pacientes, quando detalhado, funcionou como um valioso panorama para entendermos como o tema é tratado no curso médico:

Eu já vi professor nosso tentando fazer "cura gay" no ambulatório. [...] uma mãe que chegou com um questionamento sobre a sexualidade do filho e que o professor bateu no ombro dela e falou: "Nós vamos te ajudar. Claro que a gente vai conversar com ele, as coisas não são assim. Ainda dá tempo de mudar". (E10)

Todos os participantes mencionaram, como em outros estudos $^{3,5,13}$, que a temática não é valorizada pelos professores. Muitos atribuíram tal desinteresse ao desconhecimento ou à baixa capacitação técnica. Esse achado se torna preocupante quando entendemos que, nesse momento da formação, a busca do conhecimento se dá justamente em direção àquilo que eles deduzem que docentes e instituições consideram importante ${ }^{22}$.

Além disso, também foram relatadas situações em que a temática foi diminuída ou ridicularizada por professores e colegas:

Acho que, para alguns [professores], ainda tem um certo preconceito, que ainda fazem algumas brincadeirinhas pejorativas. (E5)

[...] é um grande tabu e eu acho que é por isso que toda vez que se fala de alguma coisa de assunto de sexualidade na minha turma acontece risadinha e burburinho. Tem sempre um que faz aquela brincadeira: fala que é aula de sexualidade e aí diz: "Ai, vai falar de homem e homossexual". Então começam aquelas piadinhas de menino, de um menino com o outro: "Ah, vai falar de você. Você tem que assistir porque vai falar de você." (E10)

As "brincadeiras", nesse caso, funcionam, mais uma vez, como uma defesa que impede que alunos e docentes se impliquem efetivamente na questão. É como se eles dissessem: "Não temos nada a ver com isso!"”23. Alguns localizaram o papel de barreiras culturais e pessoais na criação de um espaço 
pouco propício aos processos de reflexão e de construção do conhecimento sobre o tema ${ }^{3,29}$. As crenças religiosas, em consonância com outro estudo ${ }^{14}$, constituíram as principais barreiras para esse fato:

Eu percebi o desconforto de alguns colegas com certeza, tem pessoas que têm mais dificuldades por questões culturais, religiosas... na minha turma, tenho experiência de alguém que é de determinada religião e tem dificuldades para lidar com isso. (E1)

Assim como em outras investigações ${ }^{2,3,6-8,10,13}$, foi unânime a ideia de que desenvolver habilidades para lidar com as sexualidades e seus matizes é fundamental para a prática médico-assistencial. Quando questionados se estavam capacitados para abordar aspectos sexuais de pacientes, no entanto, todos os alunos afirmaram se sentir despreparados. O déficit da temática no currículo foi a justificativa mais recorrente:

Eu me sinto inseguro. Pode ser que já tenham técnicas na literatura de abordagem de paciente que eu não tenha a mínima intimidade pra executar. E eu também não pratiquei durante a graduação. Eu não saberia me portar. [...] Eu não me sinto seguro. (E15)

O conteúdo relativo ao "não saber", na maioria das vezes em que apareceu nas falas, foi acompanhado da responsabilização de elementos externos, como, por exemplo, o currículo, os professores, os colegas, os aspectos socioculturais, etc. Essa constatação nos remeteu ao estudo de Paulino ${ }^{15}$, que buscou compreender a postura de médicos em relação ao cuidado da população LGBT. Diante do "não saber", os entrevistados se alocavam num lugar passivo, que não lhes permitia buscar ativamente novas formas de conhecimento e de atuação. Delegar ao outro a responsabilidade pelo desconhecimento funcionava, na verdade, como justificativa socialmente aceita para que, em suas práticas, eles não precisassem se defrontar com questões relativas às diversidades sexuais: "Não cuido porque não sei, se soubesse cuidaria". Isto não significa que não exista déficit na formação, mas não basta disponibilizar conteúdos sem criar estratégias para que os atores envolvidos reconheçam a pertinência do tema e se engajem na construção do saber.

Em nossa investigação, tivemos o cuidado de não ater nossos questionamentos às especificidades dos grupos que desafiassem as normas binárias e heteronormativas que regulam o campo sexual. Em diversos momentos, quando perguntávamos sobre o ensino da sexualidade em suas diferentes dimensões, os alunos foram enfáticos em dizer que quase nunca se falava sobre o tema na graduação. Para entender melhor esse ponto, analisamos como era estruturado o currículo do curso que investigamos.

Ao contabilizarmos os títulos presentes no conteúdo programático dos programas das disciplinas obrigatórias e eletivas, observamos que 8,6\% deles (269 em um total de 3.099) se referia, de alguma forma, a aspectos relativos às sexualidades; $7,9 \%$ dos temas tratavam de aspectos estritamente biológicos tais como "Morfologia e funções do aparelho reprodutor feminino (ovários, tubas, útero e vagina)" e "Abordagem do casal infértil" - e 0,7\% tratava de aspectos psicossociais - tais como "Percepção do corpo relacionada à vida social: gênero e saúde" e "Sexualidades e gêneros e seus discursos regulatórios no campo da saúde". Diante disso, poderíamos, de fato, afirmar que não se fala de sexualidade no curso de Medicina?

Percebemos que, na verdade, se fala - e muito - sobre o tema na graduação médica, especialmente nas disciplinas de Saúde Mental, Medicina Geral da Criança, Saúde da Mulher, Medicina Geral de Adultos, Medicina Legal e Deontologia Médica. Essa abordagem, no entanto, conforme mostram outras pesquisas ${ }^{3,13}$, prioriza aspectos orgânicos, reforçando entidades binárias, naturalizadas e essencializadas. Foucault ${ }^{19}$ elucida essa questão ao defender que o exercício efetivo do poder no controle dos corpos se dá não exatamente pela via da negatividade, do silenciamento ou da repressão. Há, ao contrário, fomento à produção de práticas, discursos e saberes, que, chancelados por um conhecimento científico socialmente validado, passam a regular experiências individuais e coletivas sem que sequer percebamos.

Duarte $^{30}$ complementa que a naturalização da sexualidade se deu nos séculos XVII e XVIII, quando se estabeleceu a corrente ideológica conhecida como "fisicalismo". Nessa época, investigações anatômicas e fisiológicas culminaram na construção da ideia ocidental de um "corpo-máquina", ou seja, um corpo cuja "essência" se reduz à materialidade de seu funcionamento orgânico. Essa perspectiva cartesiana passou a sustentar o ideal de que há uma "natureza" humana que pode ser desvendada por meio de um "reducionismo fisicalista". Não é por acaso que assistimos, especialmente ao longo do século XIX, à consolidação de uma compreensão naturalizada do campo sexual com foco na anatomia, na fisiologia e na reprodução. Foi por essa via que se determinaram padrões sexuais "normais" ${ }^{23,24,26}$ que, até os dias atuais, preponderam como verdades inquestionáveis nos cursos médicos.

A naturalização desses pressupostos pôde ser localizada não só em disciplinas que abordavam o tema formalmente, mas também em situações inusitadas. É o caso, por exemplo, do relato informal de um aluno sobre uma aula de Parasito- 
logia em que o professor, ao explicar o ciclo reprodutivo do Schistosoma Mansoni, gendrificou o parasita, dizendo que, como em nossa espécie, os machos abrigam e protegem as fêmeas. As "essências" masculina e feminina são concebidas, assim, como efeitos diretos de aspectos biológicos, reforçando as normas que supõem a continuidade entre sexo-gênero-desejo.

Essa premissa delimita o conhecimento curricular, deixando de fora - e, ao mesmo tempo, criando - aquilo que se entende como "diversidades". Esse tipo de formação contribui para uma postura dos profissionais que influencia negativamente o comportamento da população geral ${ }^{3,4}$, refletindo-se na manutenção da exclusão social dos corpos que não se ajustam às "normas de gênero"24. Foi nesse sentido que, valorizando a participação dos estudantes na construção do currículo e das práticas pedagógicas, perguntamos a eles como gostariam que o tema fosse abordado na graduação. Discutiremos, a seguir, as propostas apresentadas.

\section{Propostas}

A maioria dos estudantes sugeriu que aulas teóricas expositivas seguidas de rodas de conversa seriam a estratégia pedagógica ideal para abordagem da temática. Muitos sugeriram a inserção transversal do tema durante todo o curso, especialmente nas atividades práticas de atendimentos ambulatoriais:

Pode ter isso no início da faculdade? Pode. Mas tem que ter depois! Porque você vai amadurecer durante a faculdade, $e$ essas coisas têm que ser abordadas no ciclo clínico, começando no quinto [período] e crescendo, e não abordar só lá no primeiro e nunca mais. Aí chego no sétimo período e dá uma abordagem, vem a MFC [Medicina de Família e Comunidade] e faz a consulta centrada no paciente, mas não tem uma abordagem contínua pra gente amadurecer e tal, é uma coisa picada! (E3)

Tinha que ser mais uma roda, pequenos grupos de discussão. [...] e inclusive ter a oportunidade de conversar com os próprios pacientes que procuram o atendimento em relação a isso. Acho que a aula expositiva serviria para uma introdução de conceitos iniciais. (E2)

De fato, estudos ${ }^{3,29}$ evidenciam que aulas meramente expositivas são pouco efetivas para despertar interesse e sensibilizar os alunos em relação ao tema. Propostas mais dialógicas e participativas - como rodas de conversa em pequenos grupos e uso de recursos audiovisuais - são mais adequadas para incentivar exposição de opiniões, crenças e vivências, desencadeando um debate crítico que possa promover novas atitudes e formas de atuação.
Também foi sugerida a abordagem de assuntos específicos em determinadas disciplinas, como hormonioterapia e saúde sexual e reprodutiva de mulheres que fazem sexo com mulheres na disciplina de Saúde da Mulher, além de uma discussão mais aprofundada das sexualidades na infância nas disciplinas de Pediatria. Muitos alunos ressaltaram a necessidade de ampliar o debate sobre a diversidade sexual nas disciplinas de Saúde Mental:

Eu acho que poderia ser dentro de outras disciplinas [...] a própria MFC [Medicina de Família e Comunidade], a Psiquiatria, a própria Clínica. [...] a gente tem que estar preparado pra abordar esse paciente, não só enxergar ele ali como um corpo humano que precisa de atendimento, mas de um ser humano complexo que tem suas demandas psicológicas. (E12)

Tal proposta, contudo, não veio acompanhada de qualquer problematização sobre efeitos do estigma e da exclusão social na saúde mental das pessoas que extrapolam os marcos binários e heteronormativos. Esse achado, mais uma vez, remete à tendência de naturalizar o campo sexual considerado normal e de patologizar - por meio da psicologização e/ou da psiquiatrização - as experiências que questionam esse tipo de enquadramento ${ }^{4,14,25}$.

Alguns entrevistados fizeram indicações mais específicas, como a criação de um ambulatório LGBT e a promoção de oficinas de capacitação de professores sobre o tema:

Acho que tinha que organizar um grupo dos professores pra saber o que os professores pensam, passar pra eles as ferramentas pra eles abordarem com os alunos. Porque, se não falar com os professores, mandar eles abordarem nos atendimentos, vai passar batido, como passou durante toda a minha formação. (E3)

Vale destacar que, como apontou um estudo ${ }^{31}$, muitos docentes apresentam uma postura positiva em relação à importância de abordar as sexualidades e os gêneros no curso de Medicina. Na prática, no entanto, eles não o fazem devido a uma série de fatores, incluindo a crença de que existem outros temas mais propícios para incluir no ensino em disciplinas como, por exemplo, Bioquímica - que, em suas perspectivas, são fundamentais para a formação médica. Há, assim, a aceitação de que, diante do excesso de conteúdos "mais importantes", questões relativas à diversidade sexual sejam abordadas colateralmente no currículo oculto. Ações de sensibilização para mudança de atitudes dos docentes ${ }^{3,29}$ poderiam funcionar, nesse caso, como uma estratégia para evidenciar a ampli- 
tude da temática e suas possibilidades de desdobramento no ensino de assuntos diversos.

Chamou a nossa atenção o conteúdo, recorrente nas falas de nossos entrevistados, de que era necessária uma "formalização" do tema na grade curricular, tornando obrigatório o contato com o assunto:

Eu acho interessante a gente formalizar esse tema dentro da grade, pra meio que obrigar as pessoas que não têm interesse a princípio a conhecer o tema e depois entender. [...] você oferece esse tipo de conhecimento pra pessoa obrigado, e causa esse start nela e acaba que isso abre um leque pra essas pessoas aprenderem as mais diferentes esferas que existem nesse sentido. Por isso é que acho importante a gente ter, mas tem que inserir na grade. (E8)

Se, por um lado, essa proposta pode ser interessante no sentido de efetivar a oferta de conhecimentos, por outro, há de se considerar a potência pedagógica de um tema transcendental que não se deixa apreender por delimitações estáveis e confortáveis. Em se tratando de cursos de Medicina, essa questão é patente. A congestão das cargas horárias e o privilégio do conhecimento "formal", técnico e operacional não contribuem para colocar em xeque as formas de ser e de estar na vida que são determinadas pela produção de discursos que têm o efeito de "verdades".

Tendo em vista que o processo de construção do conhecimento não se dá sem perguntas, é preciso problematizar a crença de que existe um corpo de conhecimento bem estabelecido que deve ser "transferido" para os alunos. Nesse sentido, muito mais que incorporar ao currículo, já "superpovoado", novas matérias sobre sexualidade, talvez seja o caso de fomentar estratégias que incitem a exploração, por meio de diferentes perspectivas e metodologias, do campo obscuro do "não saber" 23,27 . A potência dessa indicação reside na possibilidade de que, diante do (des)encontro com o desconhecido, ocorram interações entre sujeitos, afetos e saberes de forma a sustentar um espaço permanentemente aberto. Um espaço interseccional por excelência que, longe do sectarismo das disciplinas e do fascínio pelo conhecimento absoluto, possa contemplar discursos que não são reduzidos, complementados ou invisibilizados uns pelos outros, mas que cooperem entre si para que cada sujeito, a cada tempo, formule um saber inédito (e provisório) que possa ser aplicado à sua realidade.

Não se trata, portanto, de apostar demasiadamente em modelos pedagógicos preestabelecidos, mas de despertar, em todos os envolvidos no ensino médico, uma postura ético-política que, valendo-se das experiências, da criatividade e das brechas do próprio sistema curricular, permita a desestabilização de entidades e conceitos que riscam o destino dos corpos e promovem formas inesperadas de adoecimento. Debater tais questões é fundamental para que possamos, de fato, nos aproximar dos reais objetivos da formação médica.

\section{CONSIDERAÇÕES FINAIS}

Nesta pesquisa, retratamos como se dá o ensino das sexualidades no contexto do curso de Medicina de uma universidade pública. Os achados são semelhantes aos inquéritos nacionais e internacionais no que tange à forma como o tema é abordado. A base heteronormativa, com foco em aspectos biológicos, exclui questões históricas, sociais e subjetivas fundamentais para as práticas de cuidado.

Os alunos acreditam que a formação é insuficiente e não se sentem preparados para lidar com questões relativas às sexualidades de seus pacientes. Limitações pessoais, carência de discussões centradas na temática, despreparo de professores e sobrecarga do currículo foram alguns dos elementos apontados como obstáculos para esse tipo de aprendizagem. A ideia de que não se fala sobre o assunto no curso médico contribui para velar o fato de que se fala (e se fala muito) sobre tais questões. $\mathrm{O}$ que ocorre na verdade é que, devido à naturalização da heteronormatividade curricular, cria-se a percepção de que nada se sabe acerca da temática. Nossa investigação aponta, assim, a necessidade de reformulação qualitativa dessa abordagem, com enfoque na implementação de metodologias participativas que integrem temas já existentes na grade, valorizando experiências pessoais e promovendo o protagonismo de todos os envolvidos na construção crítica do saber. A sustentação de espaços interdisciplinares, não congestionados pelo ideal do saber absoluto, pode funcionar, nesse sentido, como estratégia potente para a criação de novas formas de conhecimento.

Ressaltamos que, dada a opção metodológica de nossa pesquisa, não esgotamos as possibilidades de abordagem do objeto investigado. Assim, nos perguntamos: haveria diferenças entre as perspectivas de alunos de acordo com suas identidades de gênero, orientação sexual e formação no ensino médio? Estudos qualitativos semelhantes que envolvam outras instituições e experiências poderiam nos dar outras indicações? Qual é a visão dos docentes a respeito do ensino das diversidades relacionadas às sexualidades e aos gêneros nos cursos médicos, considerando-se suas próprias histórias de formação acadêmica? Deixamos essas e outras questões em aberto de forma a fomentar novas pesquisas sobre o tema. 


\section{REFERÊNCIAS}

1. World Health Organization. Measuring sexual health: conceptual and practical considerations and related indicators. Geneva: WHO; 2010. Disponível em: http:/ / whqlibdoc.who.int/hq/2010/who_rhr_10.12_eng.pdf?ua=1> . Acessoem: 23 jan. 2018.

2. Rufino AC, Madeiro AP. Teaching sexuality in Brazilian medical schools. Einstein 2015; 13(1)vii-viii.

3. Rufino AC, Madeiro A, Girão MJBC. Sexuality Education in Brazilian Medical Schools. J Sex Med 2014;11(5)1110-7.

4. Negreiros RN, Ferreira BO, Freitas DN, Pedrosa JIS, Nascimento, EF. Saúde de Lésbicas, Gays, Bissexuais, Travestis e Transexuais: da Formação Médica à Atuação Profissional. Rev Bras Educ Méd 2019;43(1)23-31.

5. Cesnik VM, Zerbini T. Sexuality education for health professionals: A literature review. Estud Psicol Camp 2017; 34(1)161-72.

6. Shindel AW, Baazeem A, Eardley I, Coleman E. Sexual Health in Undergraduate Medical Education: Existing and Future Needs and Platforms. J Sex Med 2016;13(7)1013-26.

7. Urbina AAS, Soto ECJ. La confrontación de lasexualidadenlaprácticaprofesional de los futuros médicos: la mirada de lospasantes de medicina. Ciênc. SaúdeColetiva 2013;18(3)733-42.

8. Obedin-Maliver J, Goldsmith ES, Stewart L, White W, Tran E, Brenman S, et al. Lesbian, gay, bisexual, and transgender related content in undergraduate medical education. JAMA 2011;306(9)971-7.

9. Pedrosa CM, Spink MJP. A violência contra mulher no cotidiano dos serviços de saúde: desafios para a formação médica. Saudesoc 2011;20(1)124-135.

10. Facio Júnior FN, Glina S, Torres LO, Abdo C, Abdo JA, Faria G. Educationalprogramon sexual medicine for medical students: pilotproject in Brazil. TranslAndrol Urol. 2016;5(5)789-93.

11. Lima MCP, Cerqueira ATAR. Crenças sobre sexualidade entre estudantes de Medicina: uma comparação entre gêneros. RevBrasEducMéd 2008;32(1)49-55.

12. Vicente LM, Vieira EM. O conhecimento sobre a violência de gênero entre estudantes de Medicina e médicos residentes. RevBrasEducMéd 2009;33(1)63-71.

13. Rufino AC, Madeiro AP, Girão MJBC. O Ensino da sexualidade nos cursos médicos: a percepção de estudantes do Piauí. RevBrasEducMéd 2013;37(2)178-85.

14. Vitiritti B, Andrade SMO, Peres JEC. Diversidade sexual e relações profissionais: concepções de médicos e enfermeiros. Temas psicol. 2016;24(4)1389-1405.
15. Paulino DB. Discursos sobre o Acesso e a Qualidade da Atenção Integral à Saúde da População LGBT entre Médicos(as) da Estratégia Saúde da Família. Uberlândia; 2016. Mestrado [Dissertação] - Universidade Federal de Uberlândia.

16. Medeiros PF, Guareschi NMF. Políticas públicas de saúde da mulher: a integralidade em questão. RevEstudFem 2009;17(1)31-48.

17. Miranda JJ, Rodrigues T, Martins AM, Faria MA, Pereira DM, Silva PN, et al. Discursos de gênero e saúde: Debatendo a PNAISH com seus usuários. Psic. Teor. e Pesq. 2018,341-9.

18. Câmara de Educação Superior. Resolução CNE/CES 3/2014. Disponível em: http://portal.mec.gov.br/index. php?option $=$ com_docman\&view $=$ download\&alias $=15874$ -rces $003-14$ \& c a tegory_slug = ju n ho- 2014 pdf\&Itemid=30192. Acesso em 01 abr. 2017.

19. Foucault M. História da sexualidade 1: a vontade de saber. Rio de Janeiro: Editora Graal, 2009.

20. Minayo MCS. O desafio do conhecimento. São Paulo/Rio de Janeiro: Hucitec, 1992.

21. Bardin L. Análise de Conteúdo. Brasil: Edições 70 - Brasil, 2011.

22. Becker HS, Geer B, Hughes EC, Strauss AL. Boys in white: student culture in medical school. Chicago: The University of Chicago Press, 1961.

23. Louro GL. Um corpo estranho: ensaios sobre sexualidade e teoria queer. Belo Horizonte: Autêntica; 2018.

24. Butler J. Problemas de gênero: feminismo e subversão da identidade. Rio de Janeiro: Civilização Brasileira; 2003.

25. Porcino CA, Coelho MTAD, de Oliveira JF. Representações sociais de universitários sobre a pessoa travesti. Saude soc. 2018; 27(2)481-494.

26. Costa-Val A, Guerra A. Corpos trans: um ensaio sobre normas, singularidades e acontecimento político. Saude soc. 2019;28(1)121-134.

27. Freire P. Pedagogia da autonomia: saberes necessários à prática educativa. São Paulo: Paz e Terra, 1996.

28. Rufino AC, Madeiro A, Trinidad AS, dos Santos RR, Freitas I. Disclosure of Sexual Orientation Among Women Who Have Sex With Women During Gynecological Care: A Qualitative Study In Brazil. J Sex Med 2018;15(7)966-973.

29. Rufino AC, Madeiro AP. 6 Práticas Educativas em Saúde: Integrando Sexualidade e Gênero na Graduação em Medicina. RevBrasEducMéd 2017;41(1)170-178.

30. Duarte LFD. A sexualidade nas ciências sociais: leitura crítica das convenções. In: Piscitelli A, Gregori MF, Carrara $\mathrm{S}$ (org.). Sexualidade e saberes: convenções e fronteiras. Rio de Janeiro: Garamond; 2004, p.39-80. 
31. Oscar T, Charlene MR, Gareth JT. Sexuality and gender identity teaching within preclinical medical training in New Zealand: content, attitudes and barriers. N Z Med J. 2018;131(1477)35-44.

\section{CONTRIBUIÇÃO DOS AUTORES}

Alexandre Costa Val concebeu e coordenou a investigação, participou da revisão bibliográfica, da pesquisa de campo, da análise dos resultados, do desenvolvimento do texto e da aprovação da versão final. Leonardo Mendes Mesquita, Vinícius de Abreu Rocha, Hugo Alejando Cano-Prais e Gustavo Meirelles Ribeiro participaram igualmente da pesquisa de campo, da análise dos resultados, do desenvolvimento do texto e da aprovação da versão final.

\section{CONFLITO DE INTERESSES}

Não há.

\section{ENDEREÇO PARA CORRESPONDÊNCIA}

Universidade Federal de Ouro Preto, Escola de Medicina. Campus Morro do Cruzeiro - Bauxita - cep.34400.000 - Ouro Preto, MG - Brasil 